\title{
Prediction of Continuous Cooling Diagrams for the Precision Forged Tempering Steel 50CrMo4 by Means of Artificial Neural Networks
}

\author{
Florian Nürnberger, ${ }^{1}$ Mirko Schaper, ${ }^{1}$ Friedrich-Wilhelm Bach, ${ }^{1}$ Iryna Mozgova, ${ }^{2}$ \\ Kostjantyn Kuznetsov, ${ }^{2}$ Anna Halikova, ${ }^{3}$ and Olga Perederieieva ${ }^{3}$ \\ ${ }^{1}$ Institut Für Werkstoffkunde, Leibniz Universität Hannover, An der Universität 2, 30823 Garbsen, Germany \\ ${ }^{2}$ Faculty of Applied Mathematics, Dnipropetrovsk National University, Prospekt Y. Gagarina 72, 49010 Dnipropetrovsk, Ukraine \\ ${ }^{3}$ Faculty of Information Technologies, National Mining University of Ukraine, Prospekt Karla Marksa 19, \\ 49027 Dnipropetrovsk, Ukraine
}

Correspondence should be addressed to Florian Nürnberger, nuernberger@iw.uni-hannover.de

Received 23 November 2008; Accepted 24 February 2009

Recommended by Richard Hennig

\begin{abstract}
Quenching and tempering of precision forged components using their forging heat leads to reduced process energy and shortens the usual process chains. To design such a process, neither the isothermal transformation diagrams (TTT) nor the continuous cooling transformation (CCT) diagrams from literature can be used to predict microstructural transformations during quenching since the latter diagrams are significantly influenced by previous deformations and process-related high austenitising temperatures. For this reason, deformation CCT diagrams for several tempering steels from previous works have been investigated taking into consideration the process conditions of precision forging. Within the scope of the present work, these diagrams are used as input data for predicting microstructural transformations by means of artificial neural networks. Several artificial neural network structures have been examined using the commercial software MATLAB. Predictors have been established with satisfactory capabilities for predicting CCT diagrams for different degrees of deformation within the analyzed range of data.
\end{abstract}

Copyright (c) 2009 Florian Nürnberger et al. This is an open access article distributed under the Creative Commons Attribution License, which permits unrestricted use, distribution, and reproduction in any medium, provided the original work is properly cited.

\section{Introduction}

Precision forging is a technology for the production of components with near-net-shape geometry such as automotive gears. High precision forging of the geometry enables the overall process chain to be reduced since machining before heat treatment is no longer necessary. This provides the possibility of heat treating directly from the forging heat, so-called integrated heat treatment. The latter is being thoroughly investigated within the collaborative research center CRC 489 "Process Chain for the Production of precision-forged High Performance Components" at the Leibniz University of Hannover, Germany [1, 2].

Microstructural transformations during integrated heat treatment are influenced not only by high austenitising temperatures of about $1200^{\circ} \mathrm{C}$ but also by plastic deforma- tions due to the forging process. Thus, neither the usual isothermal transformation diagrams nor continuous cooling transformation diagrams from literature, for example, $[3,4]$, nor deformation diagrams investigated for rolling processes $[5,6]$ are suitable for predicting microstructural transformations during tempering from such hot-forming temperatures. On account of this, the deformation CCT diagrams for the tempering steels 34CrMo4 (SAE 4135), 42CrMo4 (SAE 4140), 50CrMo4 (SAE 4150), 51CrV4 (SAE 6150 ), and $34 \mathrm{CrNiMo6}$ (1.6582) were determined in a previous work [7] according to the standards SEP 1680 [8], SEP 1681 [9], and PN-68/H-04500 [10], respectively. Since such physical experiments are time-consuming and costly, the capabilities of artificial neural networks were investigated for predicting deformation CCT diagrams with regard to the particular processing in precision forging. 
TABle 1: Chemical composition of the investigated melts in mass $\%$.

\begin{tabular}{lccccc}
\hline Melt & 34CrMo4 & 42CrMo4 & 50CrMo4 & 51CrV4 & 34CrNiMo6 \\
\hline $\mathrm{C}$ & 0.325 & 0.410 & 0.491 & 0.467 & 0.326 \\
$\mathrm{Si}$ & 0.289 & 0.336 & 0.212 & 0.223 & 0.263 \\
$\mathrm{Mn}$ & 0.577 & 0.701 & 0.647 & 0.845 & 0.588 \\
$\mathrm{P}$ & 0.007 & 0.011 & 0.005 & 0.006 & 0.001 \\
$\mathrm{~S}$ & 0.003 & 0.025 & 0.004 & 0.017 & 0.004 \\
$\mathrm{Cr}$ & 0.945 & 0.998 & 1.039 & 1.015 & 1.433 \\
$\mathrm{Cu}$ & 0.286 & 0.380 & 0.219 & 0.223 & 0.260 \\
$\mathrm{Mo}$ & 0.132 & 0.171 & 0.133 & 0.013 & 0.126 \\
$\mathrm{Ni}$ & 0.098 & 0.191 & 0.092 & 0.083 & 1.469 \\
$\mathrm{Al}$ & 0.025 & 0.029 & 0.024 & 0.018 & 0.023 \\
$\mathrm{Nb}$ & 0.019 & 0.019 & 0.020 & 0.002 & 0.020 \\
\hline
\end{tabular}

So far, several authors have reported on the successful predictions of CCT or TTT diagrams as a function of chemical composition; however, the influence of deformation conditions, due to precision forging, has yet to be considered. An overview of the different fields of applications for neural networks in materials science is given by [11]. Malinov et al. used a back-propagation, multilayer feedforward network to predict titanium alloy TTT diagrams from their chemical compositions [12,13]. Calculations of the initial temperatures of bainite and martensite transformations for a huge number of steels have been carried out by Garcia-Mateo et al. [14]. Using multilayer perceptrons, the austenite decomposition based on a large data base of TTT and CCT diagrams was computed by Doktorowski [15]. Based on a hierarchical feed-forward network using backpropagation, Wang et al. [16] have shown the influence of carbon concentration on the transformation characteristics of steels. The capabilities for designing new steels using neural networks have been demonstrated by Trzaska and Dobrzański [17-19].

\section{Deformation-Dependent Microstructural Transformations}

To physically simulate the precision forging process, specimens of the investigated melts (see Table 1) were heated to an austenitising temperature of $1200^{\circ} \mathrm{C}$ within 30 seconds.

Following isothermal holding for 600 seconds at this temperature, the specimens were deformed by $30 \%$ and $60 \%$, respectively (strain rate $1 \mathrm{~s}^{-1}$ ). Subsequently these were linearly cooled to room temperature using cooling rates within the range of $80 \mathrm{Ks}^{-1}$ to $0.02 \mathrm{Ks}^{-1}$. As a reference, continuous cooling transformation diagrams without deformation were also determined (see Figure 1). Measurements were carried out using a dilatometer DIL $805 \mathrm{~A} / \mathrm{D}$ made by the company Baehr Thermoanalyse GmbH.

Initiating the cooling from temperatures higher than $\mathrm{Ac}_{3}$, the steels' microstructure is austenitic or face-centredcubic ( $\mathrm{fcc}$ ). As the temperature slowly decreases below this value, austenite will then transform into body-centred-cubic (bcc) ferrite containing low concentrations of carbon. As a result of this transformation, the remaining austenite's carbon content is enriched, and the austenite therefore transforms into bcc pearlite following completion of the ferrite formation. With increasing cooling rates, diffusion decreases due to the falling temperatures, and bainitic structures are formed. With further increase in cooling rates, the diffusionless transformation of austenite into tetragonal distorted martensite occurs. This microstructure typically features very high strength and hardness at the expense of reduced ductility. The aim of the integrated heat treatment of precision forged components, as in many other heat treatments, is to create a martensitic surface layer that will significantly increase wear resistance of highly stressed parts while the core of such components is to simultaneously possess bainitic or ferritic/pearlitic structures to increase the part's fatigue limit. Knowledge of microstructural transformations as a function of cooling rates thus enables one to realise the aim of an efficient process design.

\section{Modeling and Implementation of Artificial Neural Networks}

In the following, we consider the task of predicting continuous cooling transformation diagrams as an approximation problem. For this reason, we describe each curve, which indicates the initiation or completion of a microstructural transformation, with a single-valued functional dependence

$$
T=F_{i}(d, \text { time }), \quad i=\overline{1, n},
$$

where $n$ is the number of phase transformations, time is the time of initiation or completion of a microstructural transformation, $T$ is the temperature, and $d$ the degree of deformation in percent. Predicting the transformation curves can then be seen as a task of approximating $n$ functions. For the solution to this problem, splines, wavelets, and fuzzy-logic methods, and so forth, can be used.

The curves for the initiation and completion of microstructural transformations are nontrivial for classical parametric approximation methods. We therefore use feedforward neural networks ( $F N N)$ as universal approximators. As shown in [20-22], artificial neural networks with twolayers-where one is a single sigmoidal hidden layercan approximate any continuous or discontinuous function from $R^{n}$. Leshno et al. obtained a generalization of these results for neural networks with arbitrarily limited piecewise continuous activation functions [23]. According to [23], multilayer perceptrons have the capacity to approximate any continuous function to a prescribed accuracy. Similar results were achieved by Huang et al. [24] using artificial neural networks with radial-based functions (RBF). Analysis of the approximation possibilities of artificial neural networks is a common, though challenging task. Figure 2 depicts the 


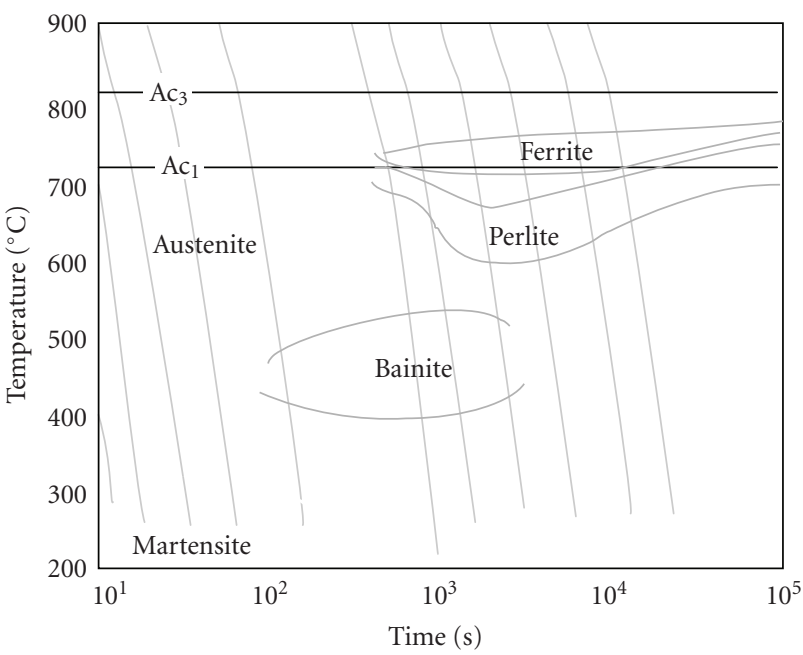

(a)

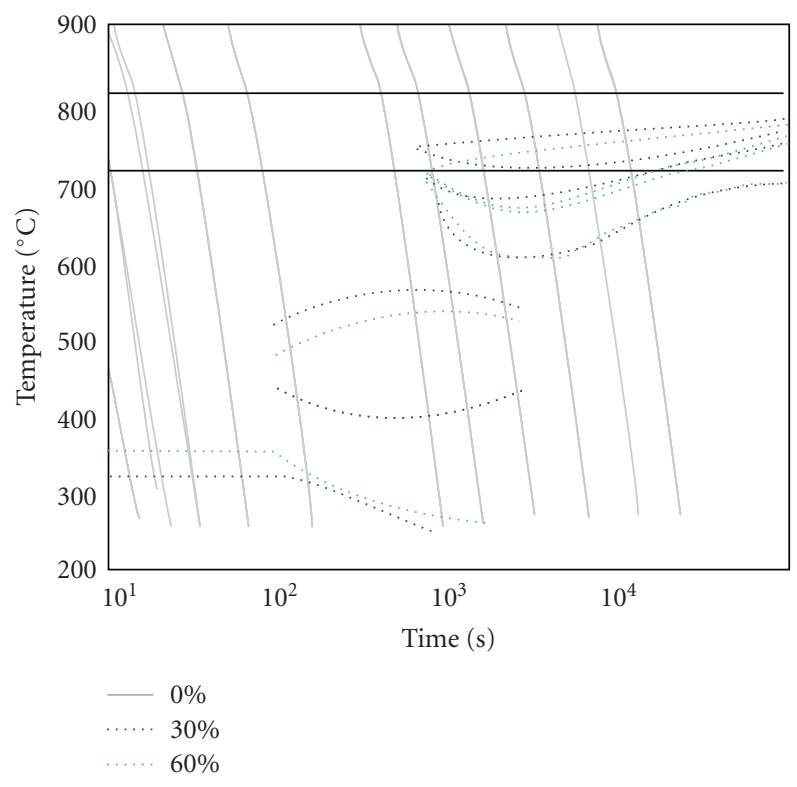

(b)

FIGURE 1: Continuous cooling transformation diagrams of tempering steel 50CrMo 4 for deformation of 30\%, $60 \%$, and $0 \%$, respectively $[7]$.

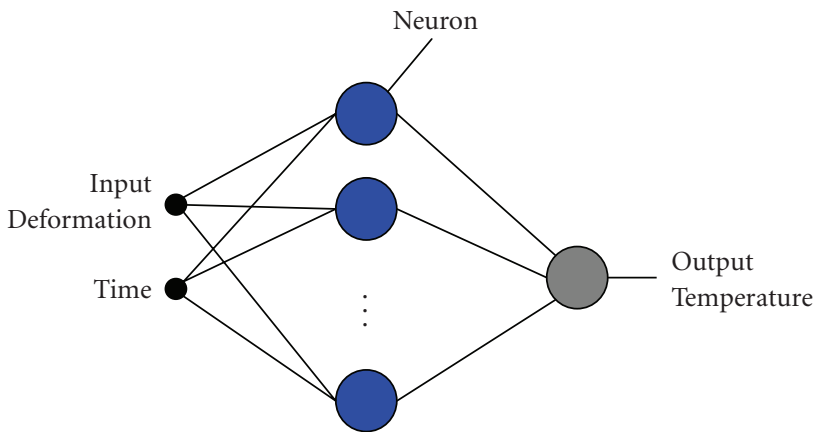

FIGURE 2: Schematic of the model of a feed-forward neural network used for predicting the transformation curves for deformation dependent continuous cooling transformation diagrams.

model of the feed-forward neural network used in this work, with a single hidden layer for approximating curves for the initiation or completion of microstructural transformations for deformation dependent CCT diagrams.

A general schematic of the applied approach for solving the approximation task is given in Figure 3.

\section{Data Extension}

Every curve of the continuous cooling transformation diagrams, which have different percentages of deformation, has its own time interval. Usually these intervals overlap each other (see Figure 4). We used smooth padding $(s p d)$ in order to extend the data to the common argument range. The procedure spd [25] is a linear extension fit to the first two and last two values (see what follows).

For equidistant time steps $h$, a pair of variate times Time $_{i}$ and temperatures $T_{i}$, where $i=\overline{0, n}$; new values are calculated using the following scheme:

$$
\begin{array}{rlrl}
\Delta T_{\text {left }} & =T_{1}-T_{0}, & & \\
\text { Time }_{-1} & =\text { Time }_{0}-h, & T_{-1}=T_{0}-\Delta T_{\text {left }}, \\
\text { Time }_{-2} & =\text { Time }_{-1}-h, & T_{-2}=T_{-1}-\Delta T_{\text {left }}, \\
\Delta T_{\text {right }} & =T_{n}-T_{n-1}, & & \\
\text { Time }_{n+1} & =\text { Time }_{n}+h, & T_{n+1}=T_{n}+\Delta T_{\text {right }} .
\end{array}
$$

This method works well for the approximation of equidistant signals [22]. For this purpose the function wextend from the Matlab Wavelet toolbox was used.

From physical experiments, curves were known for three degrees of deformation for each microstructural transformation of one melt. This data is to be approximated for other degrees of deformation in order to generate a generalization. Since the cooling trajectory is linear and starts at an initial temperature of $1200^{\circ} \mathrm{C}$, we transferred the data into a new coordinate system $(\alpha$, time), where $\alpha$ is the cooling rate. For this purpose, we approximated every curve of a microstructural transformation with a cubic spline and determined the intersection of the spline and the cooling trajectory (see Figure 5).

Figure 6(a) shows the curves of martensite initiation temperatures for different degrees of deformation in the new coordinate system. Furthermore, $T^{*}$ is a new point for $40 \%$ 


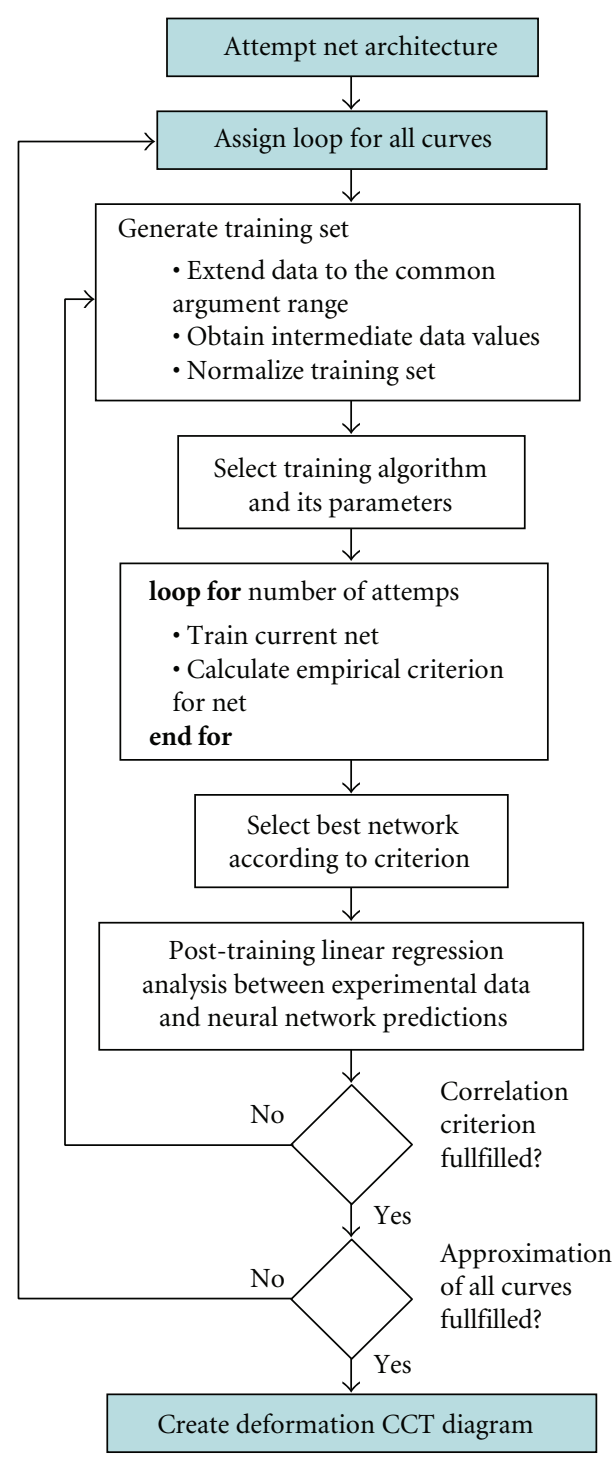

FIGURE 3: Scheme of the approach for predicting CCT diagrams.

deformation which was calculated according to the linear scheme (see Figure 6(b)). The values for the intermediate points; $10 \%, 20 \%, 50 \%, 70 \%, 80 \%$, and $90 \%$ deformation were analogously calculated.

Data inputs and outputs were normalized by a mean shift followed by a decorrelation and a covariance adjustment so that the neural network can learn more accurately.

\section{Training Algorithm Selection and Determination of the Optimal Neural Network Architecture}

Two categories of algorithms have been used. The methods of the first are based on a heuristic analysis of the behavior of the quickest descent algorithms. This category consists of variable learning rates, back-propagation, and resilient back-propagation. The second category of fast algorithms

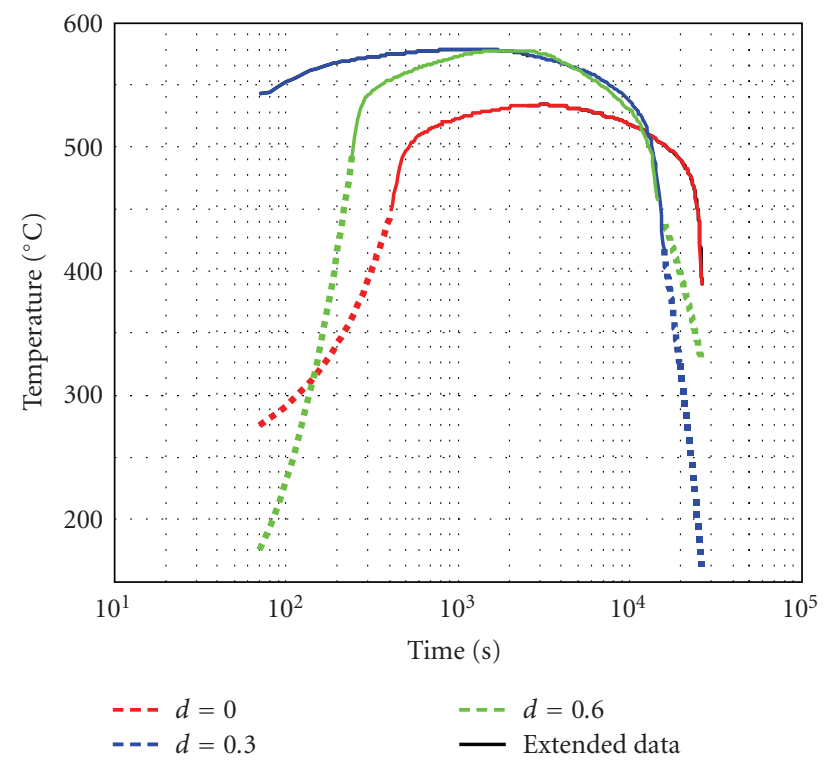

Figure 4: Data extrapolation to the common interval of microstructural transformations for different degrees of deformation $d$ using smooth padding.

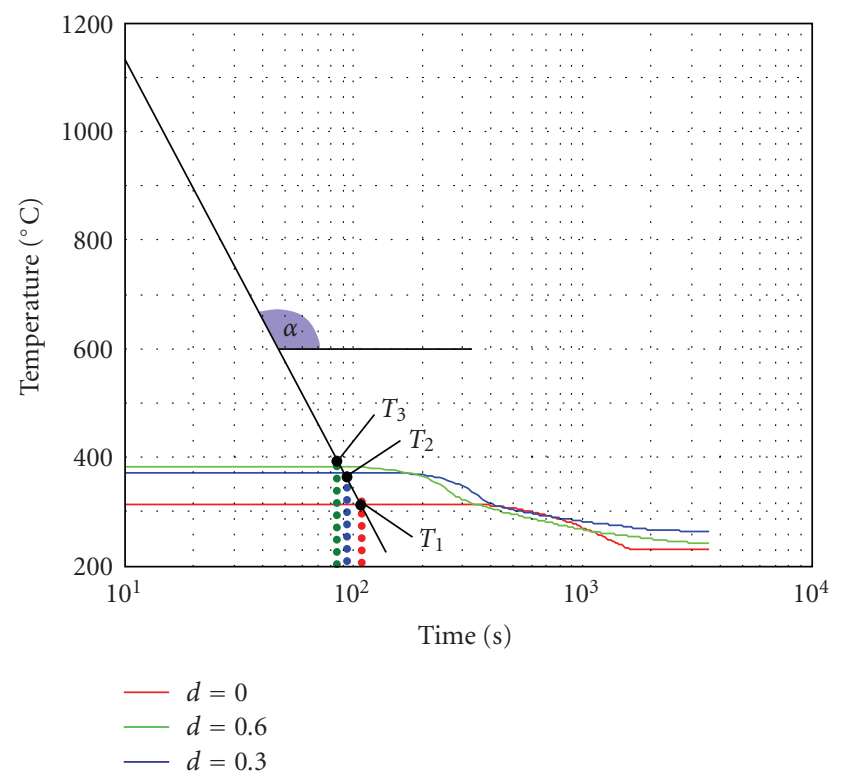

FIGURE 5: Scheme of data transformation into the ( $\alpha$, time) coordinate system.

uses methods of numerical optimization. From this category, we chose three optimization methods for network learning: Powell-Beale conjugate-gradient method, Broyden-FletcherGoldfarb-Shanno quasi-Newton, and Levenberg-Marquardt. All the algorithms mentioned work in batch mode. The algorithm Levenberg-Marquardt showed a good balance between convergence rate and generalization quality. For this reason, all further studies were carried out with this 


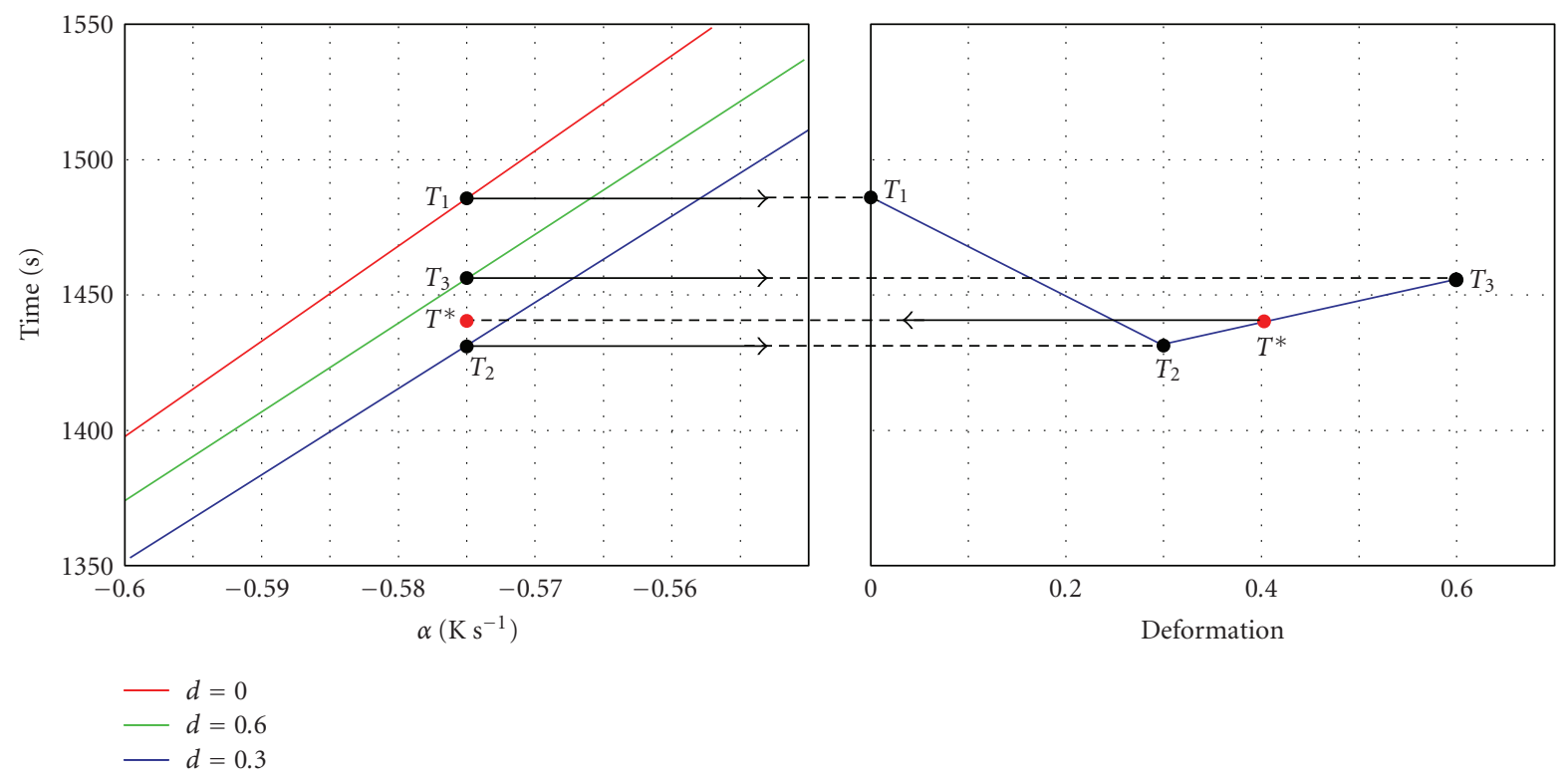

(a)

(b)

FIGURE 6: (a) Curves of martensite initiation temperature in the ( $\alpha$, time) coordinate system. (b) Scheme of linear data extension.

algorithm. Design and learning of artificial neural networks were implemented in MATLAB using the Neural Network Toolbox.

The number of neurons in the single hidden layer was varied within the range of two to fifteen in order to determine an appropriate network architecture. Ten separate training runs were carried out, and the correlation between outputs of the net and values from training sets were calculated for all the curves of microstructural transformations. Figure 7 shows the results for the bainite initiation temperatures for the tempering steel 42CrMo4 with 30\% deformation. The red polylineal curve depicts the maximum values of correlation, and the points represent the mean correlation with standard deviations calculated from ten training epochs.

This graph reveals an acceptable correlation rate of about 0.95 for nine neurons in the hidden layer. It can be seen that this correlation does not significantly increase with higher numbers of neurons. It should also be noted that the spread of data decreases at this number of neurons.

Similar results were obtained for other transformations and alloys. Thus, we used feed-forward neural networks with two inputs (degree of deformation in percent and time), one hidden layer with nine nodes and one node for output (temperature). We also used individual neural networks for each of the tempering steels and for every transformation curve. Hence, to predict the overall CCT diagram of 50CrMo4, seven neural networks are necessary. In total, the training set of every single neural network consists of 1350 to 2700 triplets (time, deformation, and temperature). The learning process was terminated when the improvement of the mean square error after 100 consecutive epochs fell below 0.01 . The best net was then selected from the ten different trained networks.

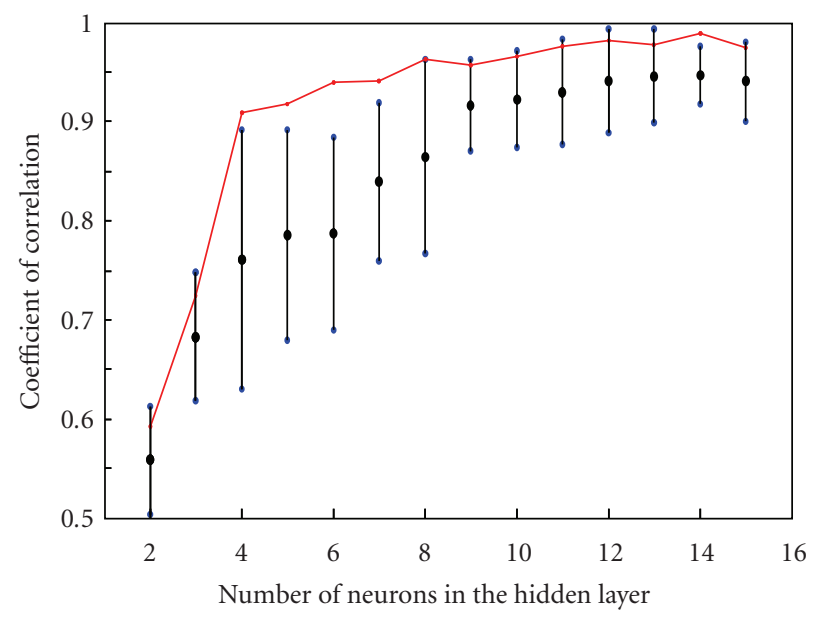

Figure 7: Mean correlation values for upper bainite with $30 \%$ deformation and varied number of neurons in the hidden layer.

\section{Results}

Figure 8 depicts the dynamics of microstructural transformations for the steel 50CrMo4. In the graphs on the left of this figure, the black curves are the network outputs, and the red curves depict the physically measured diagrams. In the graphs on the right, the transformation diagrams for unknown degrees of deformation are shown.

Figure 9 shows the correlation between measured diagrams and the net outputs.

Figures 10,11, 12, and 13 demonstrate the neural networks' performances for other types of investigated steels. 


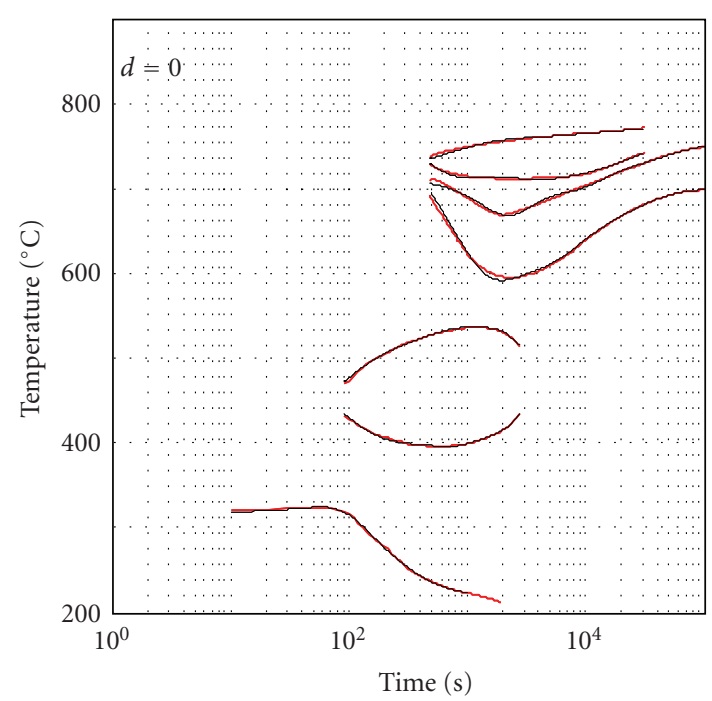

(a)

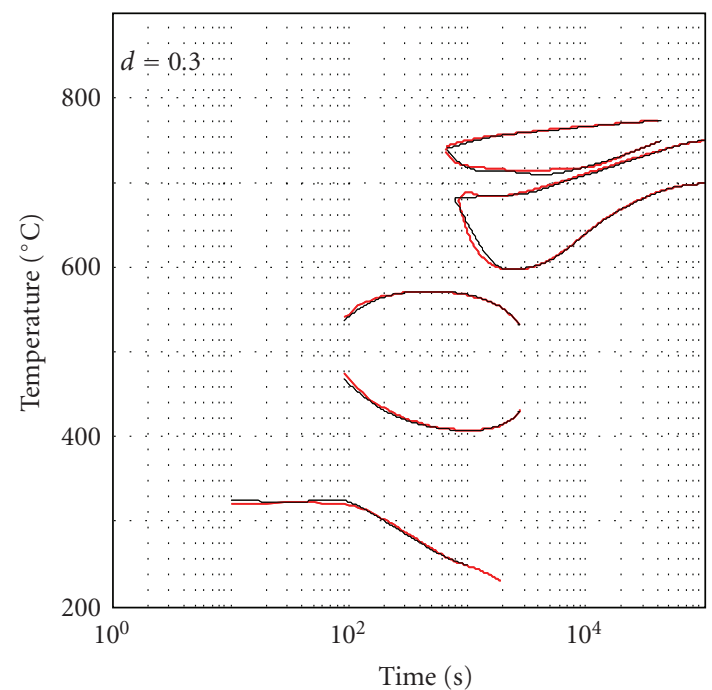

(c)

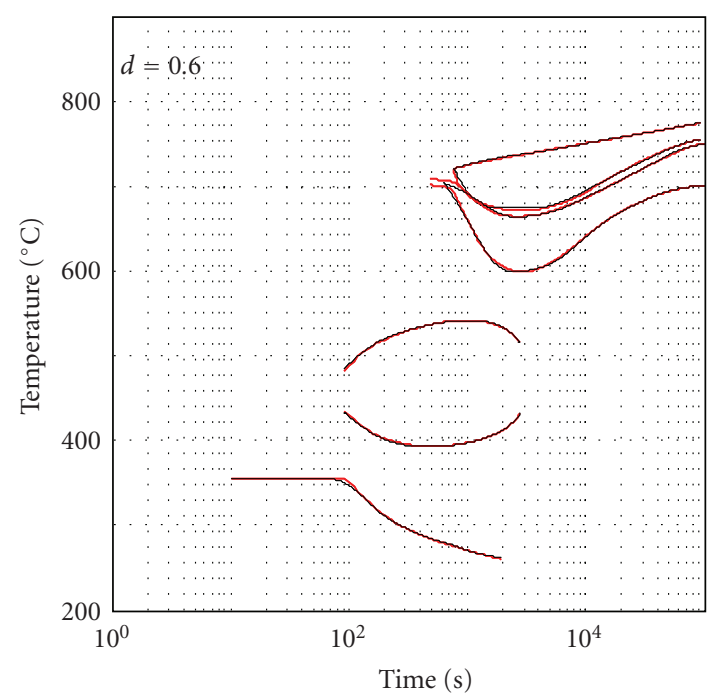

(e)

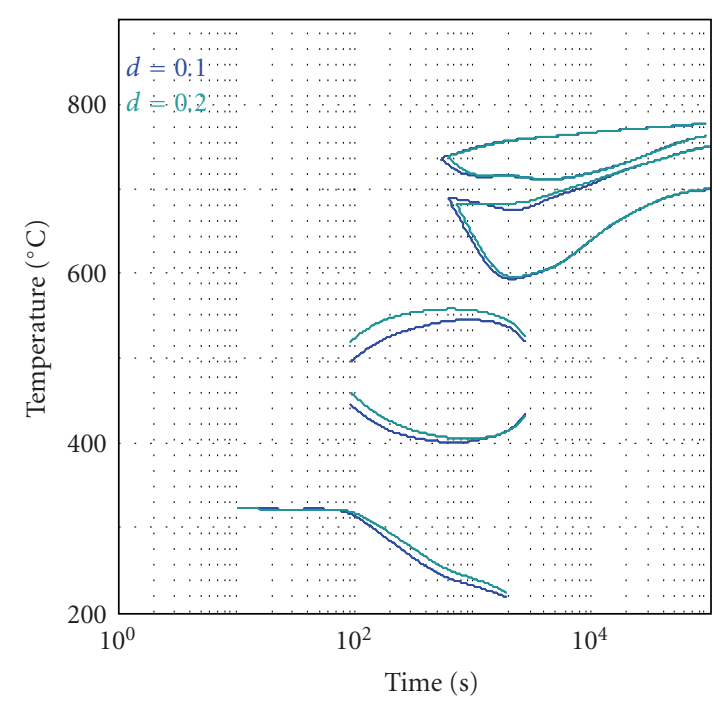

(b)

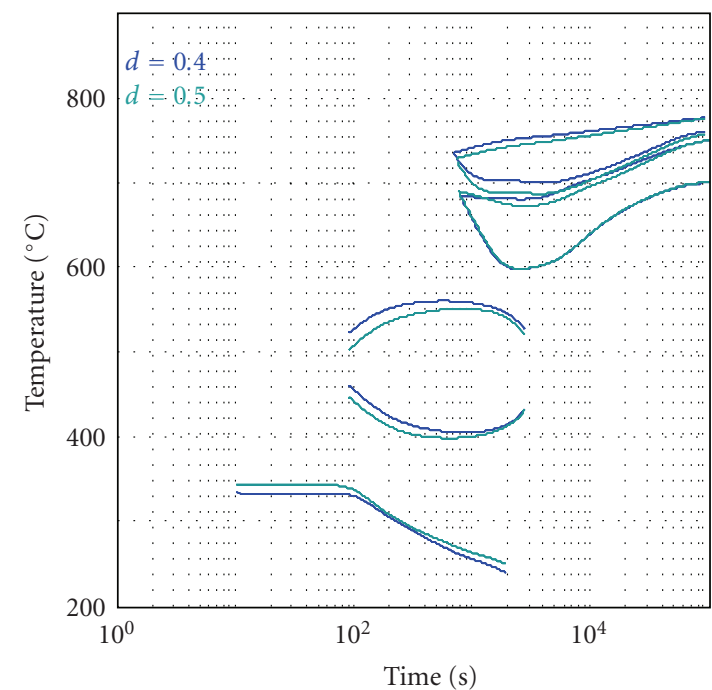

(d)

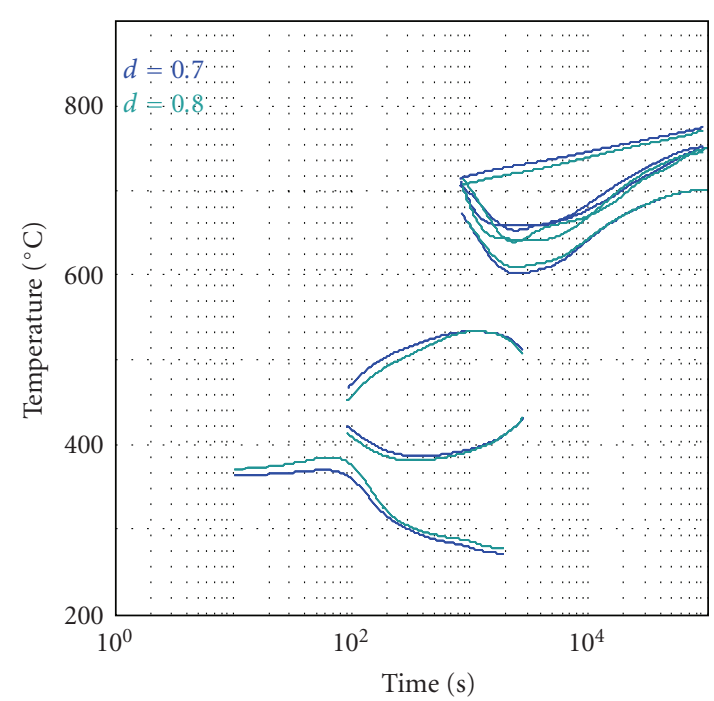

(f)

FIGURE 8: Dynamics of the microstructural transformations of the tempering steel 50CrMo4. 


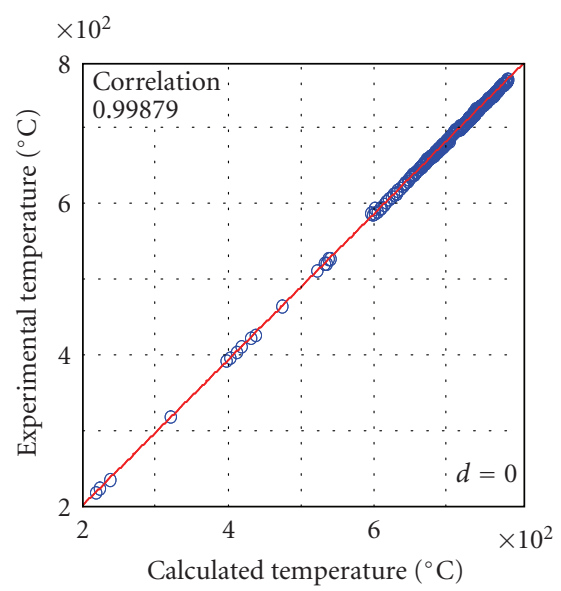

(a)

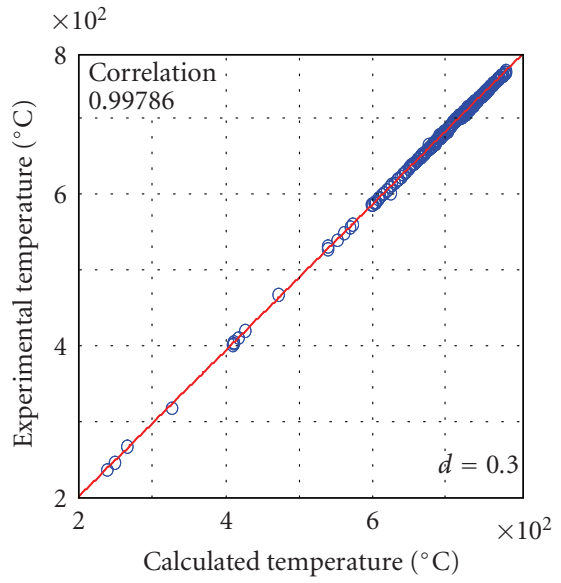

(b)

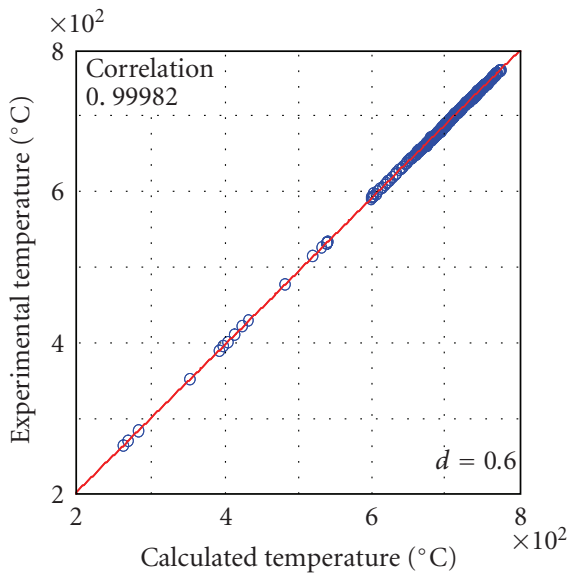

(c)

FIGURE 9: Efficiency of the neural networks for the tempering steel 50CrMo4.

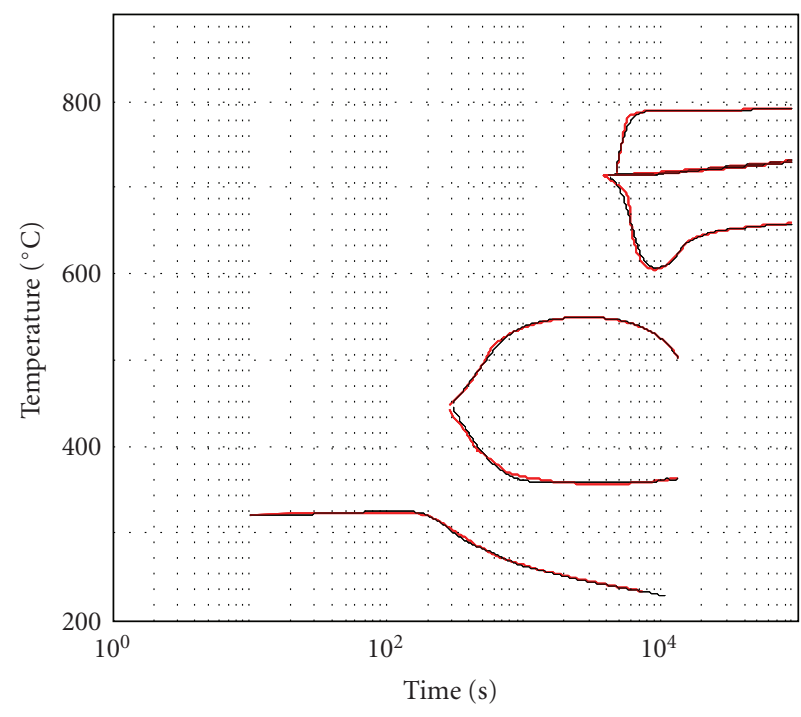

(a)

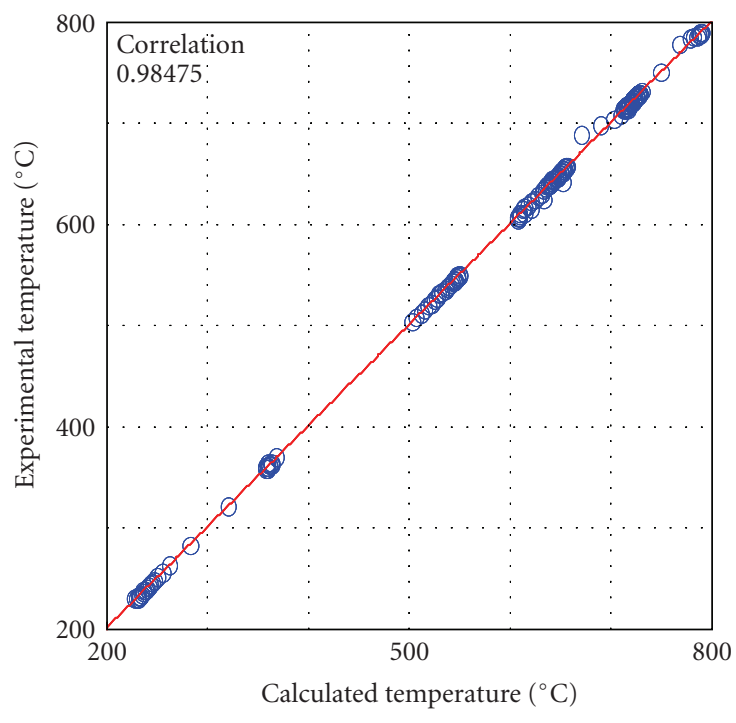

(b)

Figure 10: Results for tempering steel $42 \mathrm{CrMo} 4$ with a deformation of $0 \%$.

Results show that the artificial neural networks used here are capable of predicting the microstructural transformations within the range of the investigated degrees of deformation.

For most of the CCT diagrams, a high correlation coefficient can be achieved between the networks' output data and the experimental data.

An extrapolation beyond strains of $60 \%$ is possible; however, with further increases of deformation, the transformation lines depicting the completion of ferrite and the initiation of pearlite then begin to cross each other. This is due to the approach used where every net represents one transformation curve of a CCT diagram separated from the others. Interactions between the nets are not considered and, as a result, the overlaying effect of the curves may be observed for higher $(>80 \%)$ degrees of deformation.

\section{Further Research}

(1) The next stage of our research will be concerned with the prediction of microstructural transformations of tempering steels with lower austenitising temperatures. This will increase the data base for numerically simulating the processes of precision forging and integrated heat treatment.

Furthermore, artificial neural networks will be used for the prediction of continuous cooling transformation diagrams, not only for specified strains but also for strain 


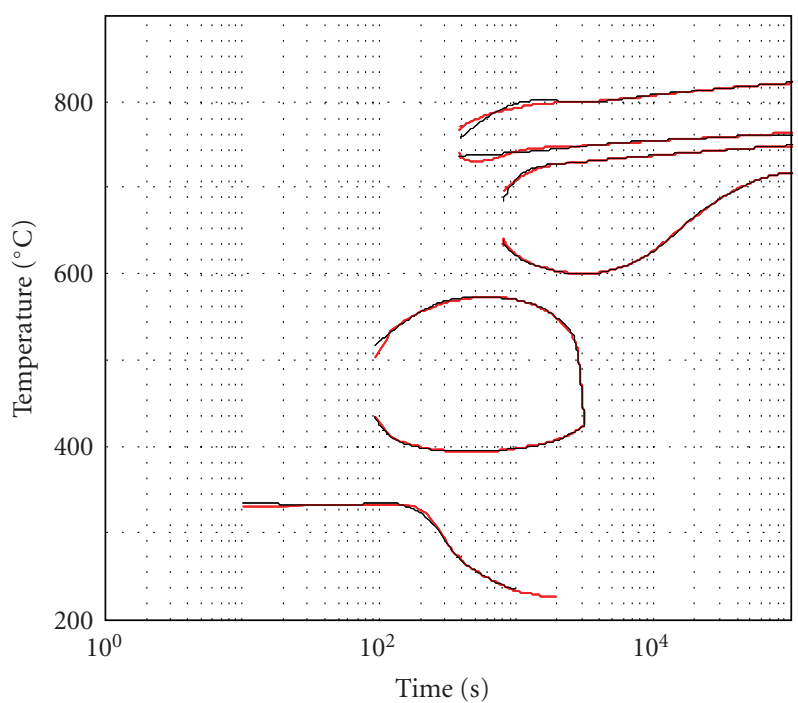

(a)

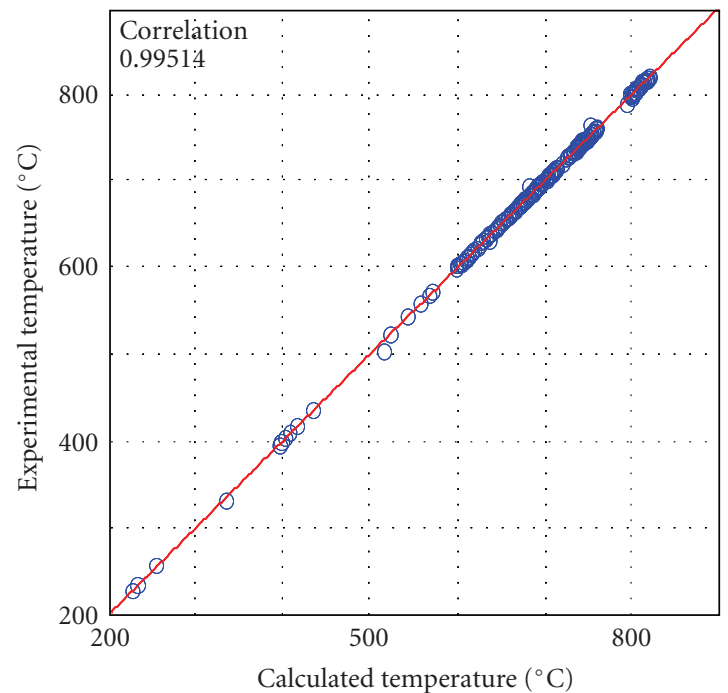

(b)

FIGURE 11: Results for tempering steel 34CrMo4 with a deformation of $0 \%$.

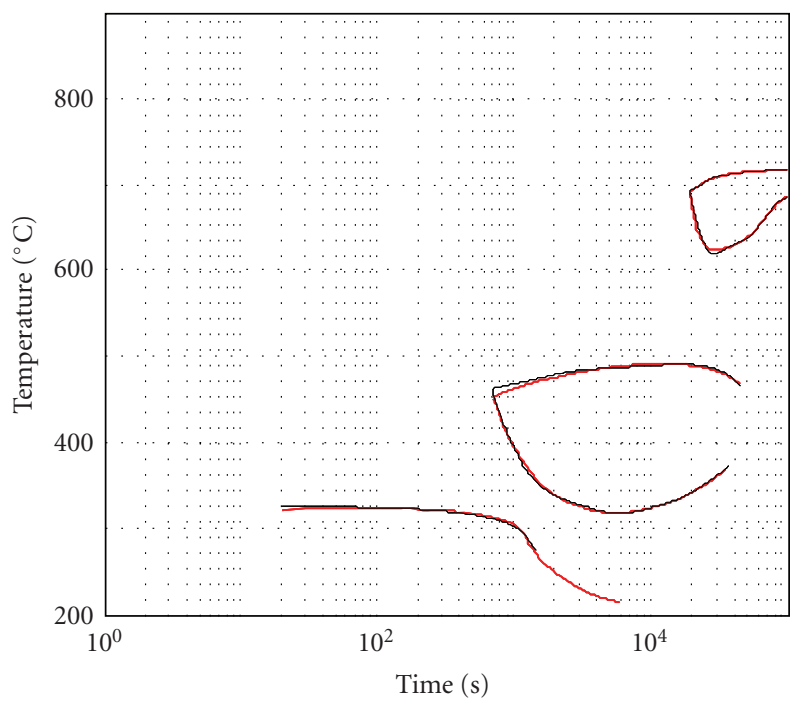

(a)

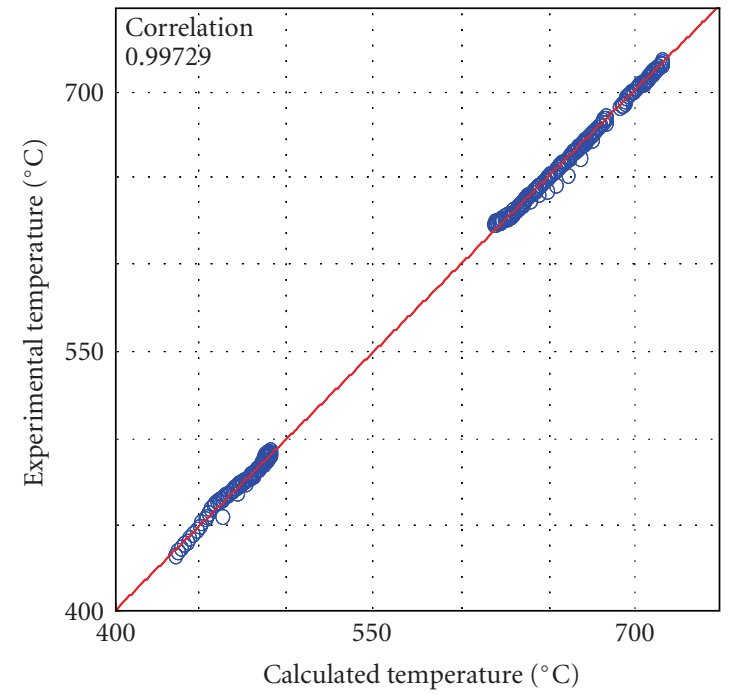

(b)

Figure 12: Results for tempering steel 34CrNiMo6 with a deformation of $0 \%$.

rates. Investigations of the CCT diagrams' strain rate dependence for the tempering steel $42 \mathrm{CrMo} 4$ are also planned for the future. These experiments may require changes in the architecture of the neural networks used.

(2) In addition to this, a certain interest lies in an alternative data handling scheme for the CCT diagrams' transformation curves to reduce the amount of data used in the training set. Therefore an approach similar to [13] will be implemented. However, we propose an application of the curves' critical points (extrema, inflections, and endpoints) of microstructural transformations.
(3) In order to avoid overfitting effects, we propose applying smoothness criteria to the predicted transformation curves. This should increase the generalization properties of the networks.

(4) The method of data extension of the current work is not applicable for processes with nonlinear cooling. For a universal approach of the diagrams generalization, it is necessary to develop an appropriate method of data extension based on other principles. Such a principle might be an algebraic method suitable for smoothed nonlinear approximated functions. 


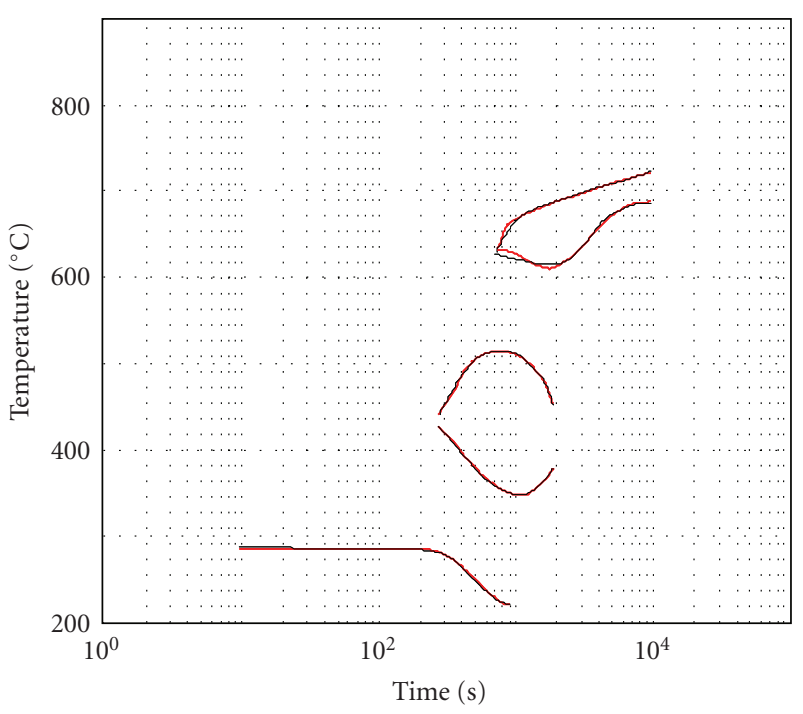

(a)

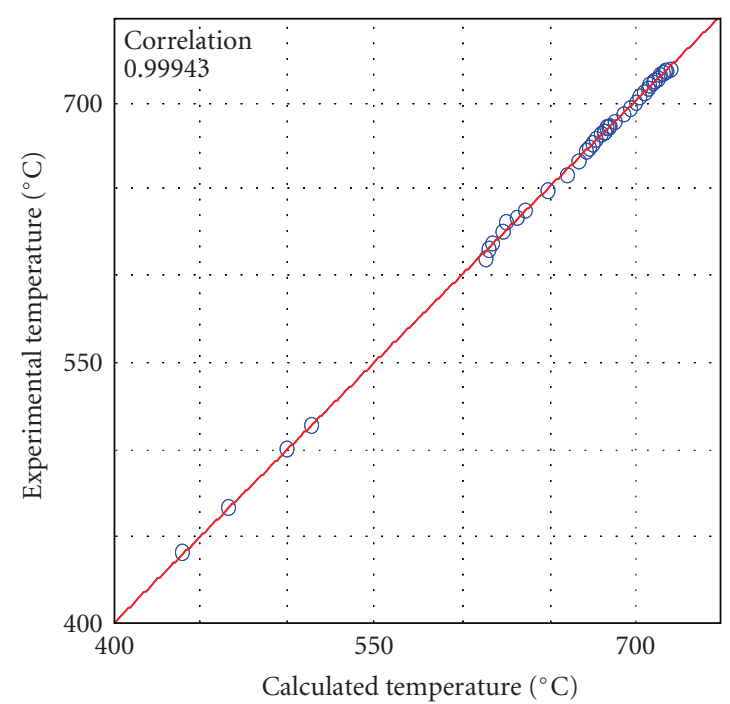

(b)

FIGURE 13: Results for tempering steel 51CrV4 with a deformation of $0 \%$.

\section{Summary}

Curves in CCT diagrams for the initiation and the completion of microstructural transformations were used as training sets for artificial neural networks. Diagrams with different deformations were utilized with regard to the process conditions of precision forging with integrated heat treatment. Predictions could be made within the range of the investigated deformation conditions. An extrapolation beyond deformations of $80 \%$ leads to inaccuracies.

\section{Acknowledgment}

The authors thank the German Research Foundation for the financial support of the research work within the collaborative research center CRC 489.

\section{References}

[1] B.-A. Behrens, E. Doege, S. Reinsch, K. Telkamp, H. Daehndel, and A. Specker, "Precision forging processes for highduty automotive components," Journal of Materials Processing Technology, vol. 185, no. 1-3, pp. 139-146, 2007.

[2] M. Bernard, M. van Well, W. Reimche, and Fr.-W. Bach, "Randzonenhärtung von Vergütungsstahl mit Sprühabschreckung_Einfluss der Düsenanordnung auf das Härteergebnis und zerstörungsfreie Bestimmung der Randzonenhärte mittels Harmonischen-Analyse von Wirbelstromsignalen," Härterei-Technische Mitteilungen, vol. 60, no. 3, pp. 150-157, 2005.

[3] F. Wever and A. Rose, Atlas zur Wärmebehandlung der Stähle. Vol. 1, Verein Deutscher Eisenhüttenleute, Stahleisen, Düsseldorf, Germany, 1961.

[4] G. F. Vander Voort, Atlas of Time-Temperature Diagrams for Irons and Steels, ASM International, Metals Park, Ohio, USA, 1991.
[5] A. Weise, Entwicklung von Gefüge und Eigenspannungen bei der thermomechanischen Behandlung des Stahls 42CrMo4., dissertation, Technische Universität Chemnitz, Chemnitz, Germany, 1998.

[6] R. Kaspar, U. Lotter, and C. Biegus, "Influence of thermomechanical treatment on the transformation behaviour of steels," Steel Research, vol. 65, no. 6, pp. 242-247, 1994.

[7] K. Kerber and Fr.-W. Bach, Eds., "Process chain for the production of precision-forged high performance components," Work Report and Renewal Proposal 2009-2010-2011, Collaborative Research Centre 489, July 2008.

[8] Stahl-Eisen-Prüfblatt. 1680-61, Aufstellung von ZeitTemperatur-Umwandlungsschaubildern für Eisenlegierungen, STAHL-EISEN-Prüfblätter (SEP) des Vereins Deutscher Eisenhüttenleute, 3rd edition, 1990.

[9] Stahl-Eisen-Prüfblatt. 1681, Guidelines for preparation, execution and evaluation of dilatometric transformation test on iron alloys, STAHL-EISEN-Prüfblätter (SEP) des Vereins Deutscher Eisenhüttenleute, 2nd edition, 1998.

[10] PN-68/H-04500, "Badania dylatometryczne metali i ich stopów," 1968.

[11] H. K. D. H. Bhadeshia, "Neural networks in materials science," ISIJ International, vol. 39, no. 10, pp. 966-979, 1999.

[12] S. Malinov and W. Sha, "Software products for modelling and simulation in materials science," Computational Materials Science, vol. 28, no. 2, pp. 179-198, 2003.

[13] S. Malinov, W. Sha, and Z. Guo, "Application of artificial neural network for prediction of time-temperaturetransformation diagrams in titanium alloys," Materials Science and Engineering A, vol. 283, no. 1-2, pp. 1-10, 2000.

[14] C. Garcia-Mateo, C. Capdevila, F. Garcia Caballero, and C. García de de Andrés, "Artificial neural network modeling for the prediction of critical transformation temperatures in steels," Journal of Materials Science, vol. 42, no. 14, pp. 53915397, 2007.

[15] A. Doktorowski, Datenbasierte Modellierung der Gefügebildung bei der gamma/alpha-Umwandlung von Stählen, dissertation, TU Bergakademie, Freiberg, Germany, 2002. 
[16] J. Wang, P. J. van der Wolk, and S. van der Zwaag, "Effects of carbon concentration and cooling rate on continuous cooling transformations predicted by artificial neural network," ISIJ International, vol. 39, no. 10, pp. 1038-1046, 1999.

[17] J. Trzaska and L. A. Dobrzański, "Modelling of CCT diagrams for engineering and constructional steels," Journal of Materials Processing Technology, vol. 192-193, pp. 504-510, 2007.

[18] L. A. Dobrzański and J. Trzaska, "Application of neural networks to forecasting the CCT diagrams," Journal of Materials Processing Technology, vol. 157-158, pp. 107-113, 2004.

[19] L. A. Dobrzański and J. Trzaska, "Application of neural networks for the prediction of continuous cooling transformation diagrams," Computational Materials Science, vol. 30, no. 3-4, pp. 251-259, 2004.

[20] K. Hornik, M. Stinchcombe, and H. White, "Multilayer feedforward networks are universal approximators," Neural Networks, vol. 2, no. 5, pp. 359-366, 1989.

[21] K. Hornik, "Approximation capabilities of multilayer feedforward networks," Neural Networks, vol. 4, no. 2, pp. 251-257, 1991.

[22] G. Cybenko, "Approximation by superpositions of a sigmoidal function," Mathematics of Control, Signals, and Systems, vol. 2, no. 4, pp. 303-314, 1989.

[23] M. Leshno, V. Ya. Lin, A. Pinkus, and S. Schocken, "Multilayer feedforward networks with a nonpolynomial activation function can approximate any function," Neural Networks, vol. 6, no. 6, pp. 861-867, 1993.

[24] G.-B. Huang, L. Chen, and C.-K. Siew, "Universal approximation using incremental constructive feedforward networks with random hidden nodes," IEEE Transactions on Neural Networks, vol. 17, no. 4, pp. 879-892, 2006.

[25] G. Strang and T. Nguyen, Wavelets and Filter Banks, WellesleyCambridge Press, Wellesley, Mass, USA, 1996. 

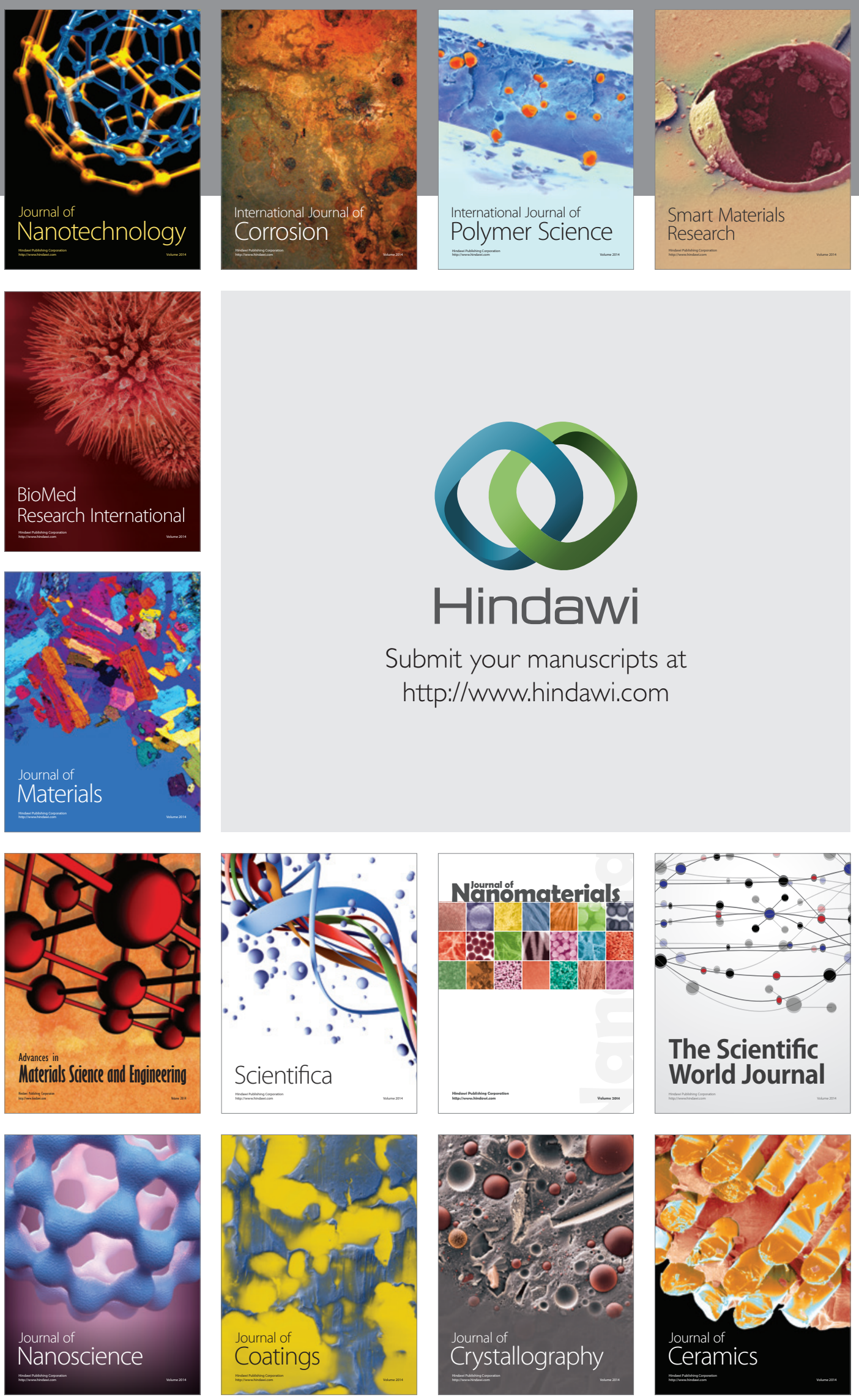

The Scientific World Journal

Submit your manuscripts at

http://www.hindawi.com

\section{World Journal}

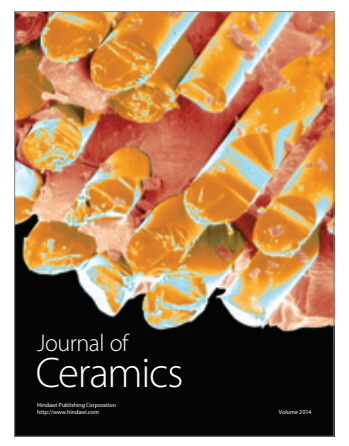

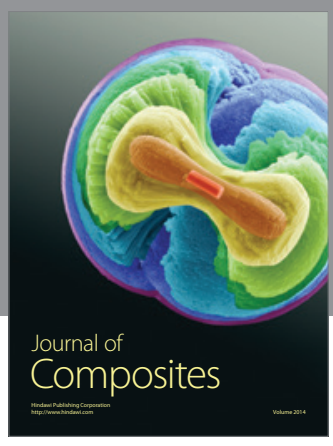
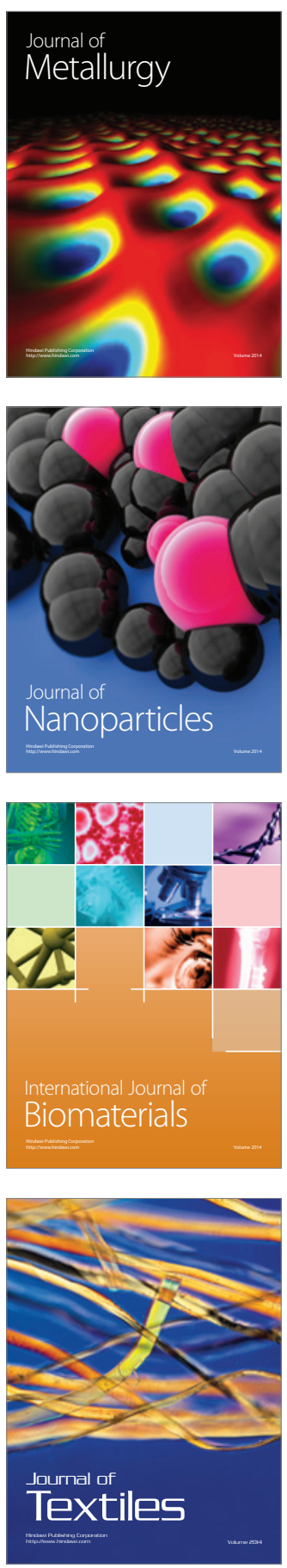